\title{
A 10 MHz GaNFET Based Isolated High Step-Down DC-DC Converter
}

Thummala, Prasanth; Yelaverthi, Dorai Babu ; Zane, Regan; Ouyang, Ziwei; Andersen, Michael A. E.

Published in:

Proceedings of The 2018 International Power Electronics Conference

Link to article, DOI:

10.23919/IPEC.2018.8506666

Publication date:

2018

Document Version

Peer reviewed version

Link back to DTU Orbit

Citation $(A P A)$ :

Thummala, P., Yelaverthi, D. B., Zane, R., Ouyang, Z., \& Andersen, M. A. E. (2018). A 10 MHz GaNFET Based Isolated High Step-Down DC-DC Converter. In Proceedings of The 2018 International Power Electronics Conference (pp. 4066-4073). IEEE. https://doi.org/10.23919/IPEC.2018.8506666

\section{General rights}

Copyright and moral rights for the publications made accessible in the public portal are retained by the authors and/or other copyright owners and it is a condition of accessing publications that users recognise and abide by the legal requirements associated with these rights.

- Users may download and print one copy of any publication from the public portal for the purpose of private study or research.

- You may not further distribute the material or use it for any profit-making activity or commercial gain

- You may freely distribute the URL identifying the publication in the public portal 


\title{
A $10 \mathrm{MHz}$ GaNFET Based Isolated High Step-Down DC-DC Converter
}

\author{
Prasanth Thummala*, Dorai Babu Yelaverthi", Regan Zane", Ziwei Ouyang*, and Michael A. E. Andersen* \\ "Electronics Group, Department of Electrical Engineering, Technical University of Denmark, \\ 2800 Kongens Lyngby, Denmark \\ \#Utah Power Electronics Laboratory, Department of Electrical and Computer Engineering, \\ Utah State University, Logan, Utah - USA 84341 \\ Email: pthu@elektro.dtu.dk, dorai.yelaverthi@usu.edu
}

\begin{abstract}
This paper presents design of an isolated high-step-down DC-DC converter based on a class-DE power stage, operating at a $10 \mathrm{MHz}$ switching frequency using enhancement mode Gallium Nitride (GaN) transistors. The converter operating principles are discussed, and the power stage design rated for $20 \mathrm{~W}$ is presented for a stepdown from 200-300 V to 0-28 V. Commercially available magnetic materials were explored and the high-frequency (HF) resonant inductor and transformer designs using a low-loss Fair-Rite type 67 material are presented. Finite element simulations have been performed to estimate the AC resistances of magnetics at $10 \mathrm{MHz}$. Experimental results are presented at $12 \mathrm{~W}, 254 \mathrm{~V}$ to $22 \mathrm{~V}$ on a laboratory prototype operating at $10 \mathrm{MHz}$. At $20 \mathrm{~W}$ the experimental prototype achieved an efficiency of $85.2 \%$.
\end{abstract}

Keywords-DC-DC conversion, Gallium Nitride, High frequency, Resonant conversion, Soft switching, Class-DE

\section{INTRODUCTION}

The motivation to operate at high switching frequency is not just to reduce the size of passive components but also to provide very fast dynamic load response. Most RF communication systems use power amplifiers (PA) to convert low-power signals into larger power RF signals for driving the antenna of a specific transmitter. The majority of PA designs utilize switched-mode pulsewidth-modulating (PWM) converters as the power source to operate RF amplifiers. Envelope tracking PAs use dynamically changing supply voltage to achieve high efficiency for the PA over the full power range. To achieve successful envelope tracking, the power supply must be capable of switching at frequencies greater than $5 \mathrm{MHz}$, as most modern RF waveforms observe a bandwidth of 1 to $5 \mathrm{MHz}$ [1], [2].

The envelope tracking power supply considered in this paper has to operate with an input voltage range of $200 \mathrm{~V}$ to $300 \mathrm{~V}$ at $10 \mathrm{MHz}$ switching frequency. Several designs at $10 \mathrm{MHz}$ switching are reported in literature for different applications. A $10-\mathrm{MHz}$ GaN 16 to $34-\mathrm{V}$ boost converter with above $90 \%$ efficiency is presented in [3]. A $94 \%$ efficient $10-\mathrm{MHz}, 100 \mathrm{~W}$ buck-boost type DCDC converter is studied in [4]. A $10 \mathrm{MHz}, 10.8-16 \mathrm{~V}$ to $0.65-2 \mathrm{~V}, 2$ A multiphase buck converter is implemented in [5]. A $10-\mathrm{MHz}, 12 \mathrm{~V}$ to $5 \mathrm{~V}, 5 \mathrm{~W}$ buck converter is investigated in [6]. All of these designs are at low operating voltage (few tens of volts).

Traditional hard switching switched-mode power supply (SMPS) topologies are extremely lossy at such high frequencies. This has led to the development of resonant soft-switching converters. With the emergence of Gallium Nitride (GaN) based power switches, power electronic converters tend to be even faster, smaller and more efficient [7]. Resonant converters are often designed in two parts; an inverter converting the DC input voltage to an $\mathrm{AC}$ current and a rectifier converting the AC current to a DC output voltage. The two parts are designed individually, but the design of the inverter depends on the input impedance of the rectifier [8], [9].

The most common topologies for the inverter part are based on class $\mathrm{E}$, which could either be a class $\mathrm{E}$, a class EF2 $(\varphi 2)$, a resonant SEPIC or a resonant boost converter. The choice of the topology is based on the complexity and losses associated with a high side gate drive for operation in the HF range. A class $\mathrm{E}$ derived inverter imposes significant voltage stress across the MOSFET. The voltage stress for the class E, the resonant SEPIC and resonant boost is 3.6 times the input voltage with a duty cycle of $50 \%$, and for the class EF 2 this stress is reduced to approximately 2.3-3 times. The semiconductor switches in the class DE inverter are directly connected to the input and the voltage across them is limited to the input voltage. The class DE inverter [10]-[12] has two other great advantages over the other topologies. Firstly, it only requires a single inductor. Secondly, due to the lower peak voltage across the MOSFET, the stored energy is approximately ten times lower.

This paper presents a GaN-based and magnetic corebased $10 \mathrm{MHz}$ isolated DC-DC converter using a ClassDE resonant soft-switching power stage. Section II describes the converter design, operation and simulation results. Section III provides the steady state analysis of the converter. Section IV discusses the choice of magnetics at $10 \mathrm{MHz}$, and the design of inductor and the transformer using Fair-Rite 67 material. Section V provides the experimental results, and Section VI 
discusses the power loss distribution, followed by the conclusions in Section VII.

\section{CONVERTER ANALYSIS AND DESIGN}

A class-DE based isolated DC-DC converter is depicted in Fig. 1. The main input power stage consists of switches $S_{1}$ and $S_{2}$. Compared to the conventional ClassDE amplifiers, the switches $S_{3}$ and $S_{4}$ are connected in parallel with the rectifier diodes $D_{3}$ and $D_{4}$, to achieve synchronous rectification and also for active rectification to control the output voltage and power. The converter achieves ZVS, zero voltage derivative switching (ZVDS), and ZCS at the turn-on instant. In this converter, the effective impedance of the secondary rectifier is used for designing the series resonant tank components $C_{r}$ and $L_{r}$. A transformer with a turns ratio $n: 1$ is used for providing isolation as well as stepping down the input voltage. The power is transferred from input to output due to the resonance between the resonant tank elements $C_{r}$ and $L_{r}$. Hence, the current flowing through the resonant tank is almost sinusoidal in shape. Based on the fundamental harmonic approximation (FHA), the ac-equivalent circuit of the proposed Class-DE DC-DC converter is shown in Fig. 2.

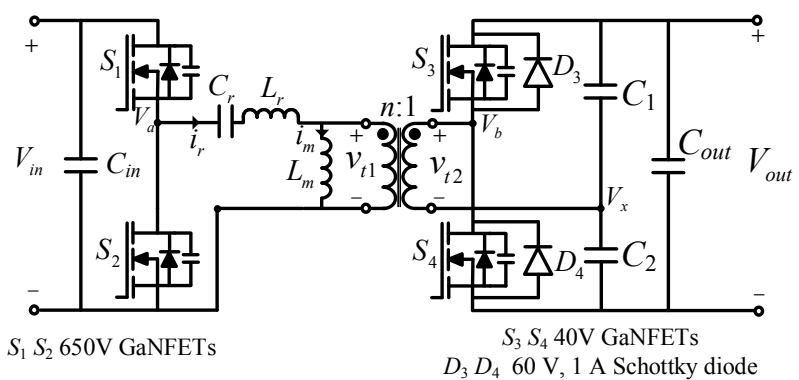

Fig. 1. Schematic of the Class-DE based isolated synchronous DC-DC converter.

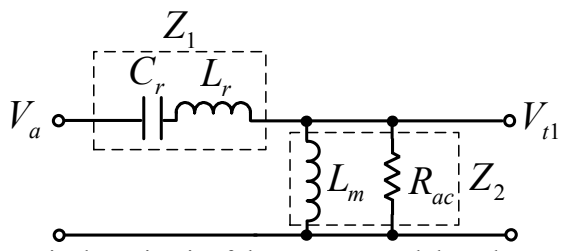

Fig. 2. AC equivalent circuit of the resonant tank based on FHA.

The design equations of the proposed isolated class-DE topology are given below. The AC equivalent load resistance (input resistance of the rectifier) is calculated as [10]

$$
R_{a c}=\frac{2 R_{L} n^{2}}{\pi\left[\pi+\omega R_{L} C_{o s s, \mathrm{sec}}\right]} .
$$

The RMS voltages on both inverter and rectifier sides of switched-nodes are given by (assuming trapezoidal waveforms) [12]

$$
\begin{gathered}
V_{a, r m s}=V_{i n} \sqrt{\frac{D_{p r i}+1}{3}}, \\
V_{b, r m s}=V_{o u t} n \sqrt{\frac{D_{\mathrm{sec}}+1}{3}} .
\end{gathered}
$$

The reactance of the resonant circuit is calculated as [13]

$$
Z_{1}=R_{a c} \sqrt{\left(\frac{V_{a, r m s}}{V_{b, r m s}}\right)^{2}-1} .
$$

The resonant tank inductance for a given tank capacitance is given by [14]

$$
L_{r}=\frac{C_{r} Z_{1} \omega+1}{C_{r} \omega^{2}}, \omega=2 \pi f_{s w} .
$$

The quality factor of the resonant tank is given by

$$
Q=\frac{1}{R_{a c}} \sqrt{\frac{L_{r}}{C_{r}}} .
$$

In the above equations, $R_{L}$ is the load resistance, $n$ is the transformer turns ratio, $D_{p r i}$ is the duty cycle of the primary GaNFETs, $D_{\text {sec }}$ is the duty cycle of the secondary GaNFETs, $f_{s w}$ is the switching frequency, and $C_{o s s, s e c}$ is the output capacitance of the secondary GaNFETs $S_{3}$ and $S_{4}$.

A transformer turns ratio of $n=2.5$ is selected to ensure both ZVS of the primary GaNFETs as well as low circulating energy of the resonant tank. An LTspice simulation of the Class-DE converter is performed using the GaNFET models from the manufacturer. On the primary and secondary sides, $650 \mathrm{~V}$ devices from GaN Systems (GS66502B) and $40 \mathrm{~V}$ GaNFET from EPC (EPC2014C) are used, respectively. The simulation results showing key waveforms are provided in Fig. 3. The primary GaNFETs from GaN Systems are driven with $6 \mathrm{~V}$ and the secondary GaNFETs from EPC are driven with $5 \mathrm{~V}$.

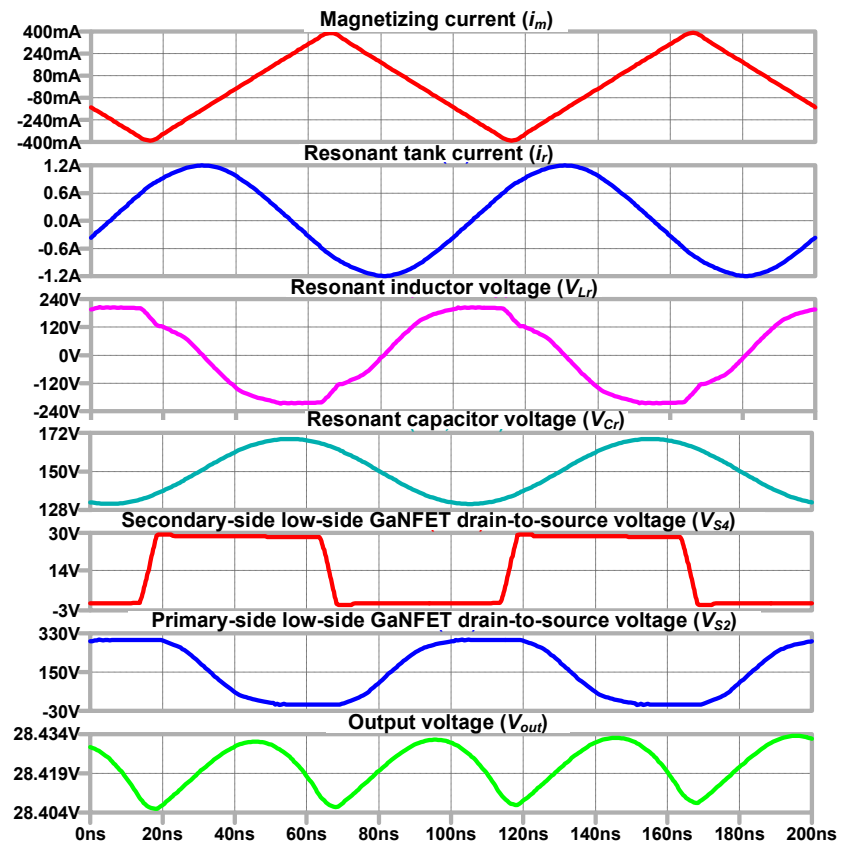

Fig. 3. LTSpice simulation results for $V_{i n}=300 \mathrm{~V}$ at $D_{p r i}=18 \%$ and $D_{\text {sec }}=40 \%$. The output power $P_{\text {out }}=20 \mathrm{~W}$. Power stage design parameters given in Table I are used in the simulation. A phase shift of $22 \mathrm{~ns}$ between primary and secondary GaNFETs is used. 
TABLE I: POWER STAGE DESIGN

\begin{tabular}{c|c}
\hline Variable & Value \\
\hline$R_{a c}$ & $49.63 \Omega$ \\
\hline$Z_{1}$ & $162.2 \Omega$ \\
\hline$C_{r}$ & $1 \mathrm{nF}$ \\
\hline$L_{r}$ & $2.8 \mu \mathrm{H}$ \\
\hline$L_{m}$ & $2.2 \mu \mathrm{H}$ \\
\hline$Z_{2}$ & $36.52 \Omega$ \\
\hline$Q$ & 1.24 \\
\hline
\end{tabular}

The design of the converter at $10 \mathrm{MHz}$ for $300 \mathrm{~V}$ input and $28 \mathrm{~V}$ output at $20 \mathrm{~W}$ is summarized in Table I. The magnetic design details are provided in Section IV.

\section{Steady State Analysis OF Class-DE DC-DC CONVERTER}

The fundamental components of the input and output voltages of the resonant tank are given by

$$
\begin{gathered}
V_{a}(t)=\frac{2 V_{\text {in }}}{\pi} \sin (\omega t), \\
V_{t 1}(t)=\frac{2 n V_{\text {out }}}{\pi} \sin (\omega t) .
\end{gathered}
$$

The voltage gain of the resonant tank is given as follows:

$$
\begin{aligned}
M & =\frac{V_{t 1}(t)}{V_{a}(t)}=\frac{n V_{\text {out }}}{V_{\text {in }}}=\frac{Z_{2}}{Z_{1}+Z_{2}} \\
& =\frac{k}{\sqrt{\left(1+k-\frac{1}{f_{n}^{2}}\right)^{2}+Q^{2} k^{2}\left(f_{n}-\frac{1}{f_{n}}\right)^{2}}},
\end{aligned}
$$

where $k=\frac{L_{m}}{L_{r}}, f_{r}=\frac{1}{2 \pi \sqrt{L_{r} C_{r}}}, f_{n}=\frac{f_{s w}}{f_{r}}$.

The voltage gain of the resonant tank $M$ is plotted in Fig. 4 with respect to the normalized frequency and the quality factor for a given constant $k$. Similarly, the voltage gain of the resonant tank $M$ is plotted with respect to the normalized frequency and the constant $k$, for a given quality factor, as shown in the Fig. 5. For the converter design specifications described in Section II, $k=0.786, f_{r}=3 \mathrm{MHz}$, and $f_{n}=3.33$.

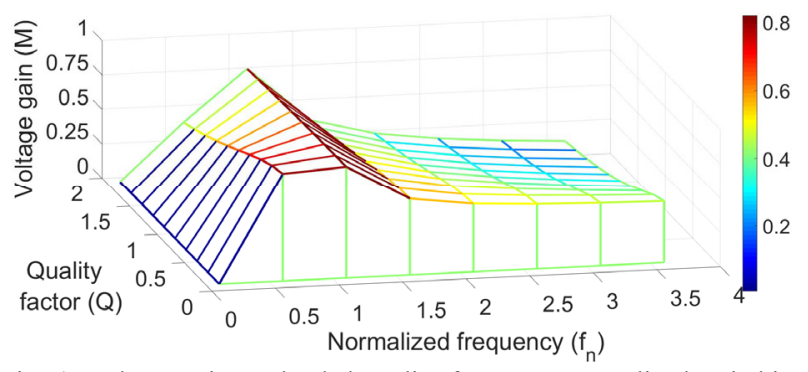

Fig. 4. Voltage gain vs. loaded quality factor vs. normalized switching frequency for $k=0.786$.

The converter is operating well above the resonance frequency so that current is lagging enough to achieve ZVS for the primary GaN devices. The $k-\mathrm{Q}$ analysis of the resonant tank for an LLC series-resonant converter (SRC) is proposed in [15]. The following condition ensures that the converter operates within LLC-SRC region [15]

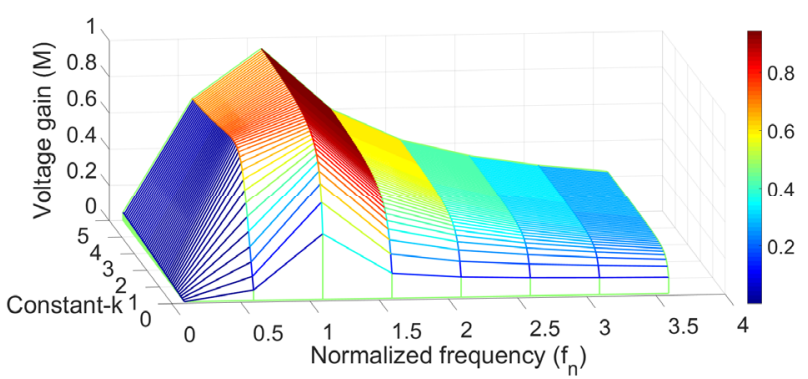

Fig. 5. Voltage gain vs. constant- $k$ vs. normalized switching frequency for $Q=1.24$.

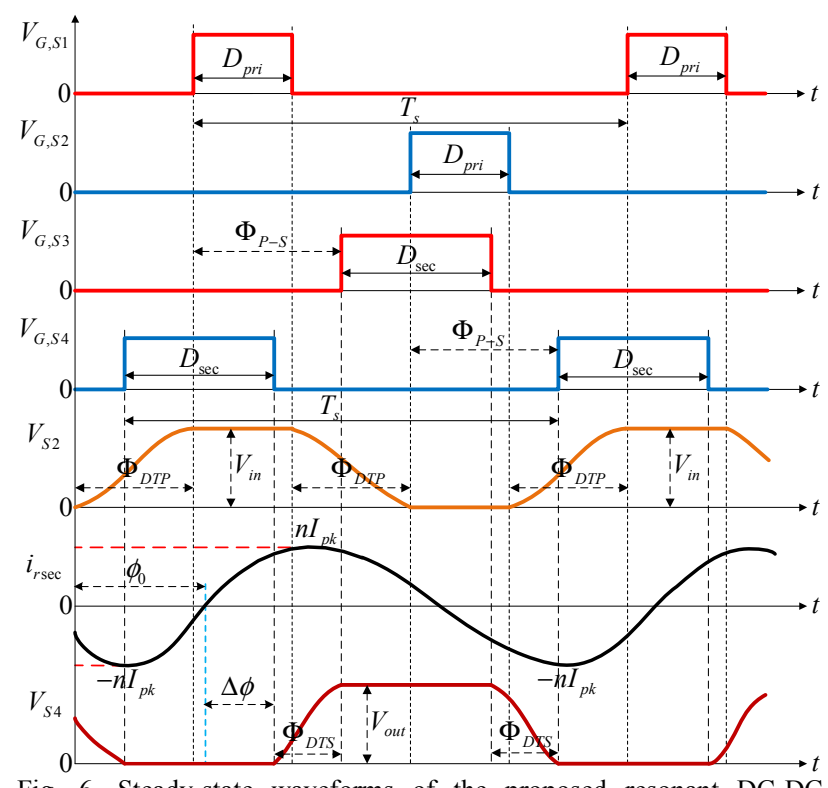

Fig. 6. Steady-state waveforms of the proposed resonant DC-DC converter.

$$
Q \leq \sqrt{\frac{L_{r}}{L_{m}}} \leq \frac{1}{\sqrt{k}} .
$$

The steady state waveforms of the proposed DC-DC converter are shown in Fig. 6. The gate drive waveforms of the four primary and secondary GaNFETs, the voltages across the GaNFETs $S_{2}$ and $S_{4}$, and the secondary resonant tank current are clearly shown in Fig. 6. The switching frequency of the converter is fixed at $10 \mathrm{MHz}$. [16]

The output power of the converter is defined as [10],

$$
P_{\text {out }}=\left(\frac{n I_{p k} \cos \left(\Delta \phi_{s}\right)}{\pi+\omega R_{L} C_{\text {oss sec }}}\right)^{2} R_{L} .
$$

The output current is given by the following expression

$$
I_{o}=\frac{n I_{p k} \cos \left(\Delta \phi_{s}\right)}{\pi+\omega R_{L} C_{o s s, \text { sec }}}
$$

The phase shift $\Delta \phi$ is given by

$$
\Delta \phi=\left(\Phi_{P-S}-\Phi_{D T S}\right)-\left(\phi_{0}-\Phi_{D T P}\right),
$$

where $I_{p k}$ is the peak resonant tank current, $\Phi_{P-S}$ is the phase-shift between primary GaNFET $S_{1}$ (or $S_{2}$ ) and 
secondary GaNFET $S_{3}$ (or $S_{4}$ ), $\Phi_{D T S}$ is the phase corresponding to the dead-time of the secondary side, $\Phi_{D T P}$ is the phase corresponding to the dead-time of the primary side, and $\phi_{0}$ is the phase-shift of the resonant current. The output power and voltage can be controlled by varying the phase-shift angle $\Phi_{P-S}$ between the primary and secondary GaNFETs. The variations of output voltage and output power with respect to the phase-shift $\Phi_{P_{-S}}$ are shown in Fig. 7. The maximum output power occurs at a phase-shift of $15 \mathrm{~ns}$ for $V_{\text {in }}=254 \mathrm{~V}$.

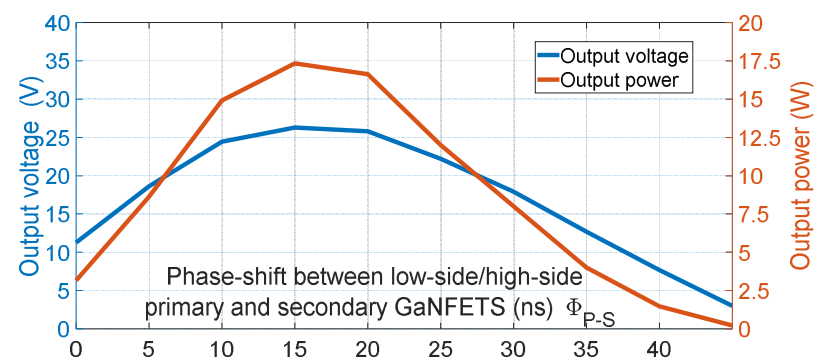

Fig. 7. The variation of output voltage and output power with respect to the phase-shift $\Phi_{P-S}$ for $V_{i n}=254 \mathrm{~V}, R_{L}=40 \Omega$.

\section{DESIGN AND FEM SimULATIONS OF MAGNETICS}

\section{A. Inductor and Transformer designs}

With the emergence of $\mathrm{GaN}$ and $\mathrm{SiC}$ devices, there has been a significant advancement in semiconductor device switching speed, but magnetics has become a primary limitation constraining miniaturization. By increasing the switching frequency of the converter, the absolute value of capacitance and inductance can be reduced but the actual size reduction at very high frequencies depends on the allowable loss in power density. Appropriate core material and winding structure have to be selected for these high frequencies to reduce the loss and realize the achievable miniaturization. Emerging thin-film magnetic materials are a good choice for frequencies greater than $10 \mathrm{MHz}$. These materials are typically alloys with $\mathrm{Fe}, \mathrm{Co}$ and Ni. But these are not commercially available at economical costs [17], [18]. Another limitation is the conductor technology. The performance factor comparisons of magnetic materials at high frequency is reported in [19]@ $900 \mathrm{~mW} / \mathrm{cc}$.

There is limited data available on the design of very high frequency power magnetics. Power magnetics have high flux drive. For most of the materials, large signal loss data are not available at above a few MHz. Among the commercially available materials, Ni-Zn ferrites and metal-powder materials, which are developed for RF applications, have very high resistivity and are suitable for the present application. The performance factor for these RF material in range of $1 \mathrm{MHz}$ to $100 \mathrm{MHz}$ are reported in [19] based on the method proposed in [20]. Performance factor is the product of amplitude of flux density $\left(B_{a c}\right)$ and frequency $(f)$ and is a measure of power handling capability per unit volume for a given core loss density and is a relevant performance metric when core loss is the major design constraint (usually true for transformers and resonant inductors), neglecting ac winding loss. Among the above reported materials, Ferroxcube 4F1 [21] and Fair-Rite 67 [22] material were available in planar structures and rest were available in rods and toroidal shapes meant for RF applications. The 67 material also has the highest performance factor at $10 \mathrm{MHz}$ [19].

For both Ferroxcube 4F1 and Fair-Rite 67 material, coreloss is plotted in Fig. 8 from raw data for $10 \mathrm{MHz}$ at $25^{\circ} \mathrm{C}$ and $100^{\circ} \mathrm{C}$ (sinusoidal current assumed through the inductor). The core loss density of 67 material is $390 \mathrm{~mW} / \mathrm{cm}^{3}$ at $10 \mathrm{MHz}, \mathrm{T}=100^{\circ} \mathrm{C}$ for $B_{a c}$ of $10 \mathrm{mT}$, and is nearly a third of what it is for $4 \mathrm{~F} 1$. Because of the relatively high thermal coefficient of the $4 \mathrm{~F} 1$, it is not a good option for fabricating a resonant inductor with low air-gap designs. For the initial prototype, 67 material was chosen as the core option for the above reasons. However, a drawback of the 67 material is that when it is exposed to $B_{a c}$ of greater than $20 \mathrm{mT}$ the material properties irreversibly change and have higher losses than the initial characteristics. Permeability of both the material at $25^{\circ} \mathrm{C}$ and $100^{\circ} \mathrm{C}$ is given in Table II. The inductor and transformer prototypes are shown in Fig. 9. The inductor and transformer designs are summarized in Tables III and IV, respectively.

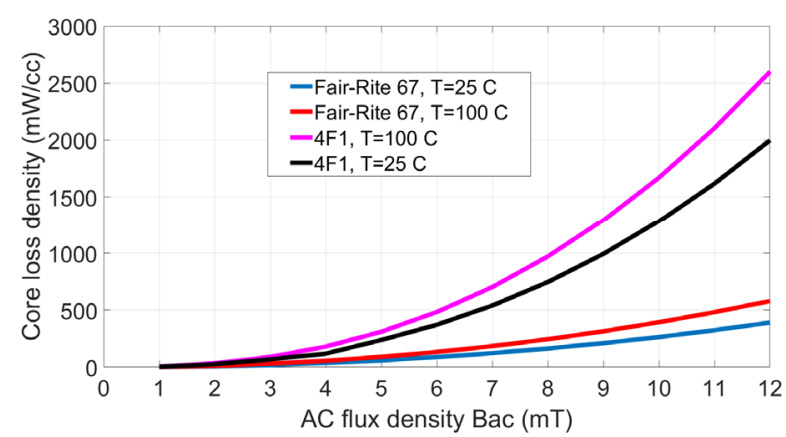

Fig. 8. 4F1 and 67 core loss density comparison at $10 \mathrm{MHz}$ and for different temperatures.

A 4-layer PCB (total thickness is $1.575 \mathrm{~mm}$ ) with $1 \mathrm{oz}$. copper thickness is used for practical implementation. To maintain the ease of manufacture and also high repeatability, multi-layered $\mathrm{PCBs}$ are used to realize the magnetic winding structures, 6-layer $\mathrm{PCB}$ for the inductor with and 8-layer PCB for the transformer. For the inductor, the copper thickness in all layers is $35 \mu \mathrm{m}$, and the $3^{\text {rd }}$ and $4^{\text {th }}$ layers are parallel connected. In the transformer, the 5 primary turns are placed in the first 5 layers, the $6^{\text {th }}$ layer in the PCB is kept empty, and the 2 secondary turns are placed in $7^{\text {th }}$ and $8^{\text {th }}$ layers, respectively. Providing an empty $6^{\text {th }}$ layer not only provides isolation between the primary and secondary windings, but it also minimizes the inter-winding capacitance. In Tables III and IV, the measured AC resistance values are used to calculate the winding loss.

TABLE II: 4F1 AND 67 PERMEABILITY WITH TEMPERATURE

\begin{tabular}{|c|c|c|}
\hline Material & $\begin{array}{c}\text { Permeability } @ \\
T=25^{\circ} \mathrm{C}\end{array}$ & $\begin{array}{c}\text { Permeability @ } \\
\mathbf{T}=\mathbf{1 0 0}^{\circ} \mathbf{C}\end{array}$ \\
\hline 4F1 & 80 & 140 \\
\hline 67 & 40 & 45 \\
\hline
\end{tabular}




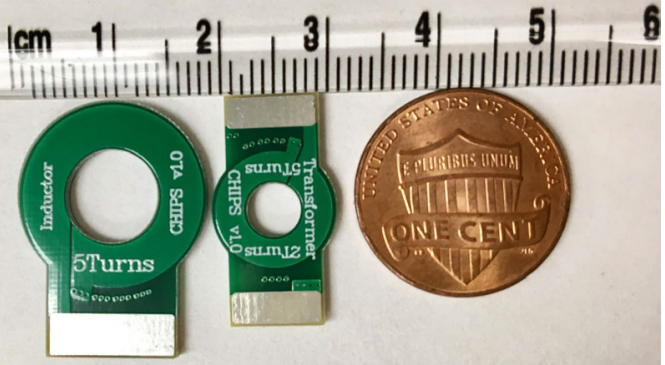

Fig. 9. A photo of inductor and transformer PCB winding prototypes.

TABLE III: INDUCTOR DESIGN SUMMARY

\begin{tabular}{|c|c|c|}
\hline \multicolumn{2}{|c|}{ Parameter } & Value \\
\hline \multicolumn{2}{|c|}{ Inductance } & $2.8 \mu \mathrm{H}$ \\
\hline \multicolumn{2}{|c|}{ Core } & $\begin{array}{c}\text { EEQ20, } 67 \text { material, } \\
\text { Volume }=2.01 \mathrm{~cm}^{3}, \text { Area }=0.6 \mathrm{~cm}^{2}\end{array}$ \\
\hline \multicolumn{2}{|c|}{ Overall core height } & $12.7 \mathrm{~mm}$ \\
\hline \multicolumn{2}{|c|}{ Effective core length } & $3.33 \mathrm{~cm}$ \\
\hline \multicolumn{2}{|c|}{ Turns, Air-gap } & 5 turns, No Air-gap \\
\hline \multirow{2}{*}{ Core loss } & (a) $20 \mathrm{~W}$ & $0.68 \mathrm{~W}\left(@ B_{a c}=11.2 \mathrm{mT}\right)$ \\
\hline & (a) $12 \mathrm{~W}$ & $0.46 \mathrm{~W}\left(@ B_{a c}=9.3 \mathrm{mT}\right)$ \\
\hline \multirow{2}{*}{ Copper loss } & (a) $20 \mathrm{~W}$ & $0.16 \mathrm{~W}\left(\right.$ for $\left.I_{r m s}=0.831 \mathrm{~A}\right)$ \\
\hline & (a) $12 \mathrm{~W}$ & $0.11 \mathrm{~W}\left(\right.$ for $\left.I_{r m s}=0.683 \mathrm{~A}\right)$ \\
\hline \multicolumn{2}{|c|}{ AC resistance @ $10 \mathrm{MHz}$} & $231 \mathrm{~m} \Omega$ \\
\hline \multicolumn{2}{|c|}{ Copper thickness } & $35 \mu \mathrm{m}$ (in all layers) \\
\hline \multicolumn{2}{|c|}{ PCB } & $\begin{array}{l}6 \text { layer (layers } 3 \text { and } 4 \text { are paralleled) } \\
\text { Total PCB thickness }=1.75 \mathrm{~mm}\end{array}$ \\
\hline \multicolumn{2}{|c|}{$\begin{array}{c}\text { PCB thickness between layers } \\
\{1-2,3-4 \text {, and } 5-6\}\end{array}$} & $0.254 \mathrm{~mm}$ \\
\hline \multicolumn{2}{|c|}{$\begin{array}{l}\text { PCB thickness between layers } \\
\qquad\{2-3 \text { and } 4-5\}\end{array}$} & $0.38 \mathrm{~mm}$ \\
\hline
\end{tabular}

TABLE IV: TRANSFORMER DESIGN SUMMARY

\begin{tabular}{|c|c|c|}
\hline \multicolumn{2}{|c|}{ Parameter } & Value \\
\hline \multicolumn{2}{|c|}{ Transformation ratio $n$} & 2.5 \\
\hline \multicolumn{2}{|c|}{ Primary magnetizing inductance } & $2.18 \mu \mathrm{H}$ \\
\hline \multicolumn{2}{|c|}{ Core } & $\begin{array}{c}\text { EIQ13, } 67 \text { material, } \\
\text { Volume }=0.28 \mathrm{~cm}^{3}, \text { Area }=0.2 \mathrm{~cm}^{2}\end{array}$ \\
\hline \multicolumn{2}{|c|}{ Overall core height } & $3.95 \mathrm{~mm}$ \\
\hline \multicolumn{2}{|c|}{ Effective core length } & $1.39 \mathrm{~cm}$ \\
\hline \multicolumn{2}{|c|}{$\begin{array}{c}\text { Turns } \\
\text { Non-interleaved: PPPPPSS }\end{array}$} & $\begin{array}{l}5 \text { turns primary, } \\
2 \text { turns secondary }\end{array}$ \\
\hline \multirow{2}{*}{ Core loss } & (a) $20 \mathrm{~W}$ & $0.055 \mathrm{~W}\left(@ B_{a c}=8.7 \mathrm{mT}\right)$ \\
\hline & (a) $12 \mathrm{~W}$ & $0.038 \mathrm{~W}\left(@ B_{a c}=7.3 \mathrm{mT}\right)$ \\
\hline \multirow{2}{*}{ Copper loss } & (a) $20 \mathrm{~W}$ & $0.265 \mathrm{~W}$ (for $I_{r m s}=0.831 \mathrm{~A}$ ) \\
\hline & (a) $12 \mathrm{~W}$ & $0.18 \mathrm{~W}\left(\right.$ for $\left.I_{r m s}=0.683 \mathrm{~A}\right)$ \\
\hline \multicolumn{2}{|c|}{$\begin{array}{l}\text { AC resistance referred to primary } \\
\text { @ } 10 \mathrm{MHz}\end{array}$} & $385 \mathrm{~m} \Omega$ \\
\hline \multicolumn{2}{|c|}{ Copper thickness } & $\begin{array}{c}35 \mu \mathrm{m} \text { (in top and bottom layers) } \\
17.5 \mu \mathrm{m} \text { (in all middle layers) }\end{array}$ \\
\hline \multicolumn{2}{|c|}{ PCB } & $\begin{array}{l}8 \text { layers, layer } 6 \text { is not used } \\
\text { Total PCB thickness }=2 \mathrm{~mm}\end{array}$ \\
\hline \multicolumn{2}{|c|}{$\begin{array}{l}\text { PCB thickness between layers } \\
\{1-2,3-4,5-6 \text {, and } 7-8\}\end{array}$} & $0.254 \mathrm{~mm}$ \\
\hline \multicolumn{2}{|c|}{$\begin{array}{l}\text { PCB thickness between layers } \\
\qquad\{2-3,4-5 \text {, and } 6-7\}\end{array}$} & $0.257 \mathrm{~mm}$ \\
\hline
\end{tabular}

Analytical analysis was done for estimating the AC resistance and optimal copper thickness to minimize the losses in both the transformer and inductor PCB windings. However, a more detailed FEM analysis is required for operation at $10 \mathrm{MHz}$ to improve the design due to the importance of parasitic effects from aspects such as PCB traces and vias.

\section{B. FEM simulations}

Maxwell's 3D simulations have been performed to estimate the $\mathrm{AC}$ resistance and leakage inductance of magnetics at $10 \mathrm{MHz}$. The FEA simulation results of the transformer current density and flux density at $10 \mathrm{MHz}$ are shown in Figs. 10(a) and 10(b). The skin depth of copper at $10 \mathrm{MHz}$ is $20.6 \mu \mathrm{m}$. A fine mesh based on inside length selection is used to simulate the eddy current effects in the winding. In the primary and secondary windings, the layer to layer connections are made through the vias with an outer diameter of $0.45 \mathrm{~mm}$ and the size of the hole is $0.2 \mathrm{~mm}$. In the transformer 3D simulation model, the vias are placed between 2 layers (layer-to-layer).

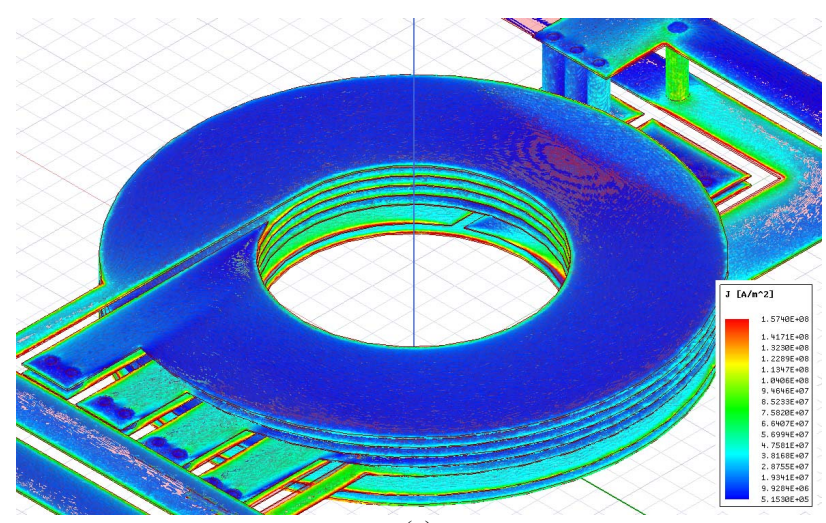

(a)

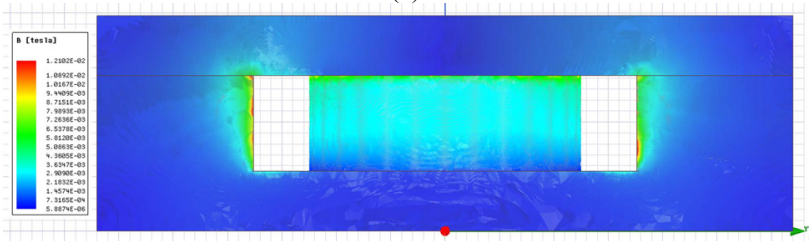

(b)

Fig. 10. Plots from the 3D Maxwell simulations of EIQ-13 transformer (a) Current density at $10 \mathrm{MHz}$; (b) Magnetic flux density at $10 \mathrm{MHz}$. Secondary winding is shorted to obtain the AC resistance and leakage inductance.

The parameters of the transformer are measured using the Agilent 4294A impedance analyzer. The measurement results are shown in Figs. 11-14.

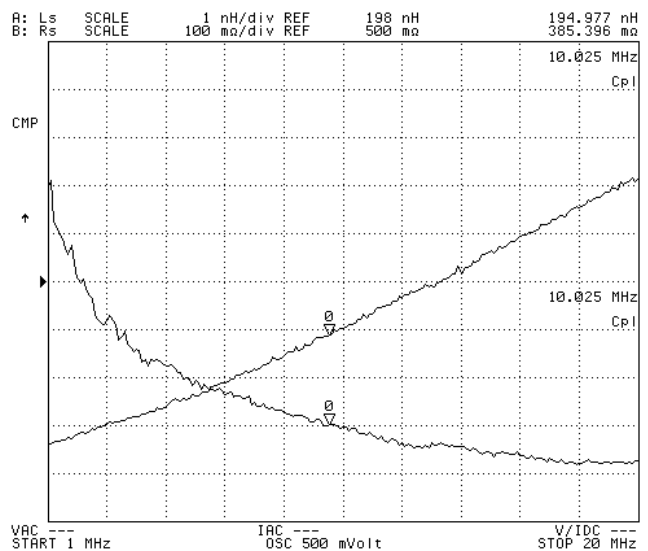

Fig. 11. Measured AC resistance and leakage inductance of the transformer using Agilent 4294A analyzer.

From Fig. 12, the resonance frequency of the transformer is $48.5 \mathrm{MHz}$, and the primary magnetizing inductance of the transformer at $10 \mathrm{MHz}$ is $2.18 \mu \mathrm{H}$ as 
shown in Fig. 13, which results in a primary transformer self-capacitance of $4.95 \mathrm{pF}$. The measured interwinding capacitance of the transformer as shown in Fig. 14 is $8.99 \mathrm{pF}$ at $10 \mathrm{MHz}$. It is obtained by shorting the primary and secondary windings, and measuring the capacitance across the shorted primary and secondary windings.

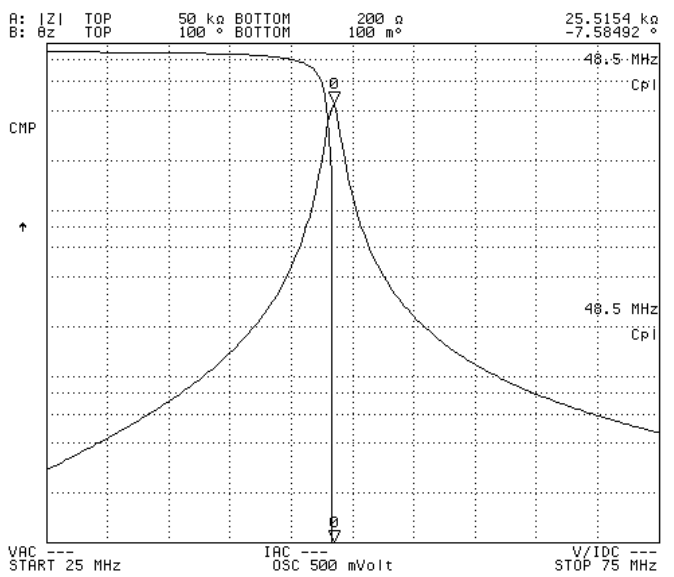

Fig. 12. Measured impedance of the transformer.

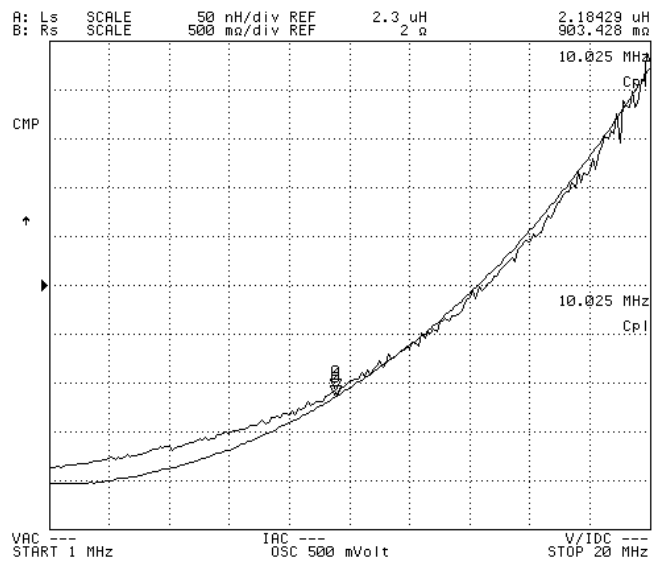

Fig. 13. Measured primary magnetizing inductance of the transformer.

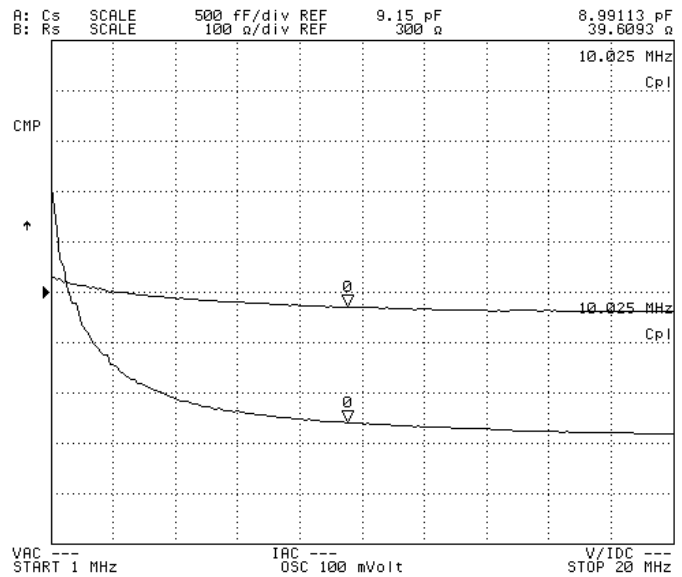

Fig. 14. Measured interwinding capacitance of the transformer.

A comparison of the simulated and measured parameters of the transformer is provided in Table $\mathrm{V}$. The simulated and measured transformer parameters show a close match, with the largest error in the $\mathrm{AC}$ resistance. The simulation model of PCB vias can be further improved to match with practical values at $10 \mathrm{MHz}$ switching frequency.
TABLE V: COMPARISON OF SIMULATED AND MEASURED TRANSFORMER PARAMETERS AT $10 \mathrm{MHz}$

\begin{tabular}{c|c|c}
\hline Variable & Simulation & Measurement \\
\hline Primary magnetizing inductance & $2.17 \mu \mathrm{H}$ & $2.18 \mu \mathrm{H}$ \\
\hline AC resistance & $300 \mathrm{~m} \Omega$ & $385 \mathrm{~m} \Omega$ \\
\hline Leakage inductance & $188 \mathrm{nH}$ & $194 \mathrm{nH}$ \\
\hline DC resistance & $40 \mathrm{~m} \Omega$ & $45 \mathrm{~m} \Omega$ \\
\hline
\end{tabular}
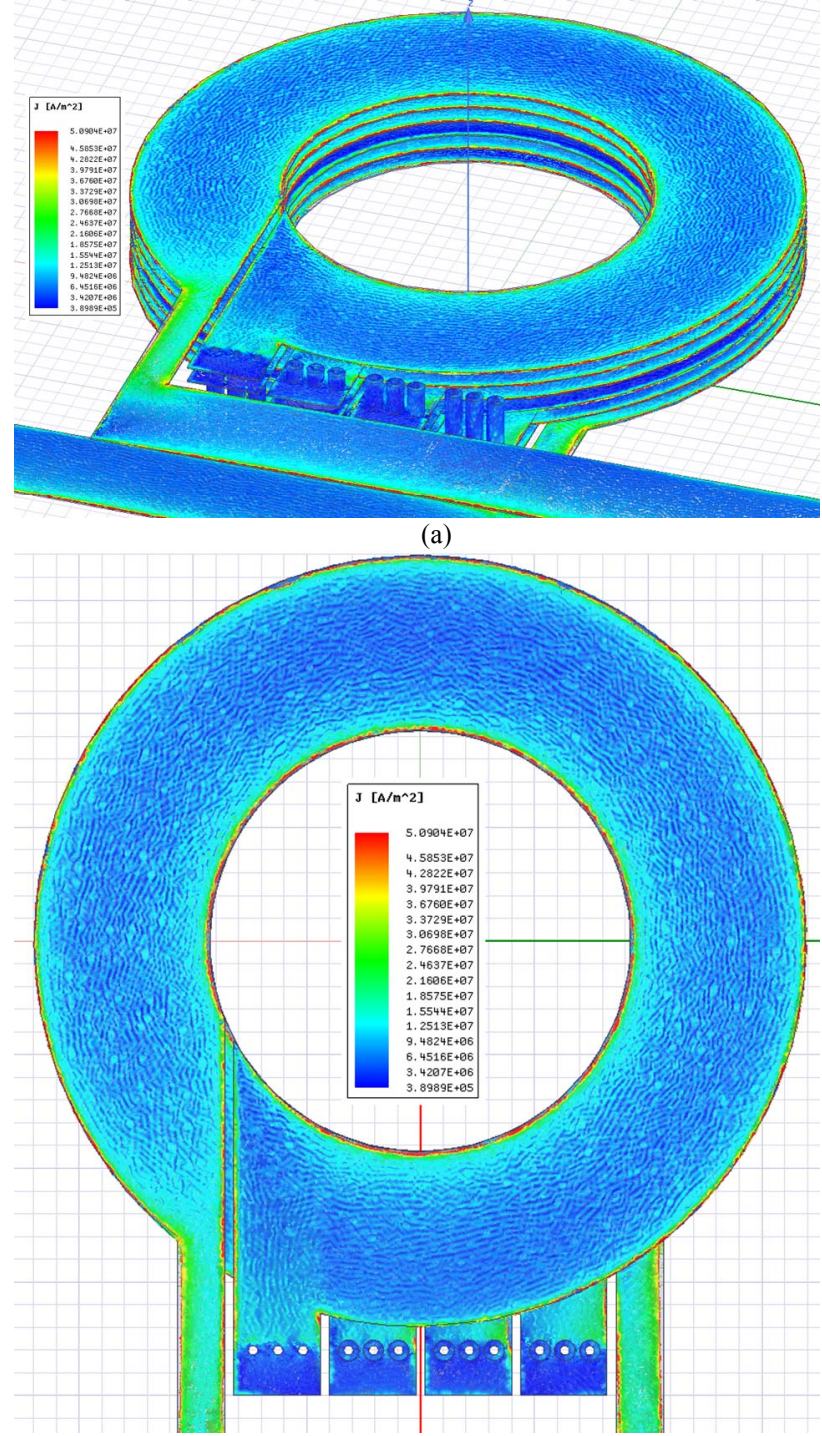

(b)

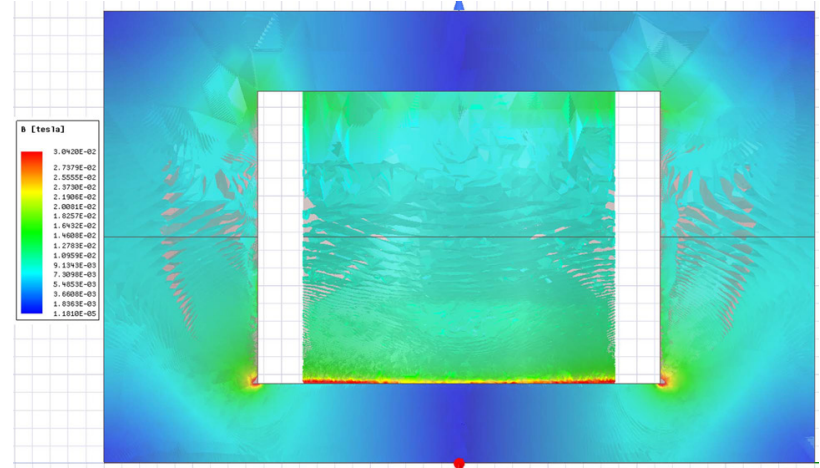

(c)

Fig. 15. Plots from the 3D simulations of EEQ-20 inductor (a) Current density at $10 \mathrm{MHz}$; (a) Current density top view at $10 \mathrm{MHz}$; (c) Magnetic flux density at $10 \mathrm{MHz}$.

The FEA simulation results of the inductor current density and flux density at $10 \mathrm{MHz}$ are shown in Figs. 
15(a), 15(b) and 15(c), respectively. As shown in Fig. 15(b), the current is pushed towards the edges of the winding. In the inductor $3 \mathrm{D}$ simulation model, the vias pass through all layers (top-layer to bottom-layer). The measured parameters of the inductor using the impedance analyzer are shown in Fig. 16.

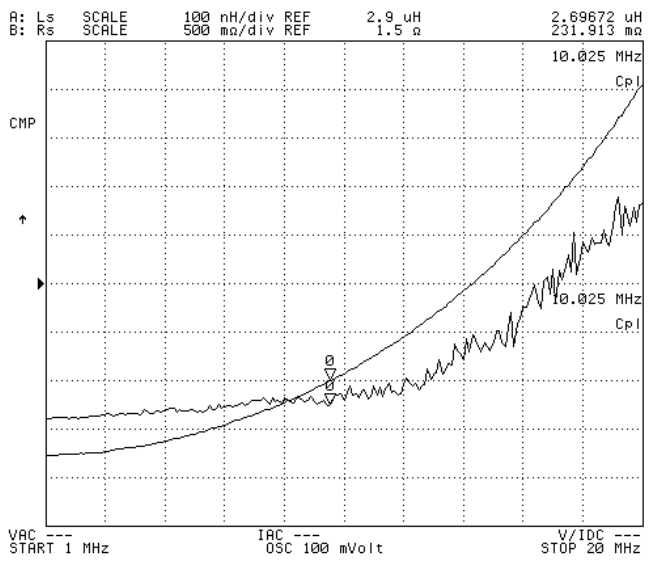

Fig. 16. Measured AC resistance and inductance of the EEQ-20 inductor using Agilent 4294A analyzer.

A comparison of the simulated and measured inductance and $\mathrm{AC}$ resistances of the inductor is provided in Table VI. Again, a close match is achieved with the largest error in the $\mathrm{AC}$ resistance. The error is primarily due to differences in how the vias are modeled. In the practical implementation of magnetics, the vias are connected from top layer to bottom layer in the PCBs.

TABLE VI: COMPARISON OF SiMULATED AND MEASURED INDUCTOR

\begin{tabular}{c|c|c}
\multicolumn{3}{c}{ PARAMETERS AT $10 \mathrm{MHz}$} \\
\hline Variable & Simulation & Measurement \\
\hline Inductance & $2.89 \mu \mathrm{H}$ & $2.69 \mu \mathrm{H}$ \\
\hline AC resistance & $131 \mathrm{~m} \Omega$ & $231 \mathrm{~m} \Omega$ \\
\hline DC resistance & $37.5 \mathrm{~m} \Omega$ & $40 \mathrm{~m} \Omega$ \\
\hline
\end{tabular}

\section{EXPERIMENTAL RESULTS}

An experimental prototype of the Class-DE based converter is shown in Fig. 17. The resonant converter is operated along a narrow optimized trajectory to guarantee ZVS and ZCS. Inductance and noise coupling in the gate drive loop is critical for operation at high input voltages. For the practical implementation, primary $650 \mathrm{~V}$, $220 \mathrm{~m} \Omega$ GS66502B GaNFETs with low output capacitance $(17 \mathrm{pF})$ and gate charge $(1.7 \mathrm{nC})$ are used. For synchronous rectification, $40 \mathrm{~V}, 60 \mathrm{~m} \Omega \mathrm{EPC} 2014 \mathrm{C}$ GaNFETs $\left(C_{o s s}=150 \mathrm{pF}, Q_{g}=2 \mathrm{nC}\right)$ are used in the secondary side. A HF diode PMEG6010CEH is used for $D_{3}$ and $D_{4}$. The experimental results are provided in Figs. 18 and 19.

High-frequency resonant capacitors from ATC are used for $C_{r}, C_{1}$ and $C_{2}$. A $1000 \mathrm{~V}, 1 \mathrm{nF}$ capacitor (100C102JW) is used for $C_{r}$ [23]. A $100 \mathrm{~V}, 684 \mathrm{nF}$ capacitor (900C684MP) is used for $C_{1}$ and $C_{2}$ [24]. A digital isolator $\mathrm{ADuM} 210 \mathrm{~N}$ with common mode transient immunity $(\mathrm{CMTI}) \geq 100 \mathrm{~V} / \mu \mathrm{s}$ is used for isolation. Due to non-availability of commercially available half-bridge gate drivers suitable for $300 \mathrm{~V}$ input and $10 \mathrm{MHz}$ operation, and to quickly evaluate the power stage design, a battery powered isolated low-side gate driver
LM5114 [25] is used for driving each GaNFET. All gatedrivers for switches $S_{1}-S_{4}$ have been designed with a negative-bias supply ( -2 or $-3 \mathrm{~V})$ to prevent false turn-on. Negative bias voltage in switch $S_{2}$ can be seen from Fig. 18. Independent gate drive resistors $R_{g, O N}(20 \Omega)$ and $R_{g, O F F}(3.3 \Omega)$ are used to counter Miller effect on primary side. The inductance and noise coupling in gate drive loop are very critical for operation of converter at $10 \mathrm{MHz}$. A Virtex-5 FPGA development board is used to generate the required $10 \mathrm{MHz}$ driving signals on both primary and secondary sides.

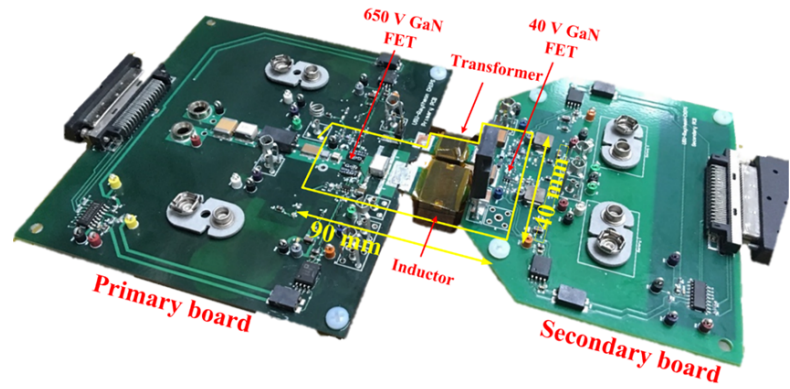

Fig. 17. An experimental prototype of the Class-DE based converter. The $10 \mathrm{MHz}$ switching power stage is outlined in yellow. The rest of the PCB has connectors to the FPGA board, digital isolators, test points and auxiliary supplies for gate drivers.

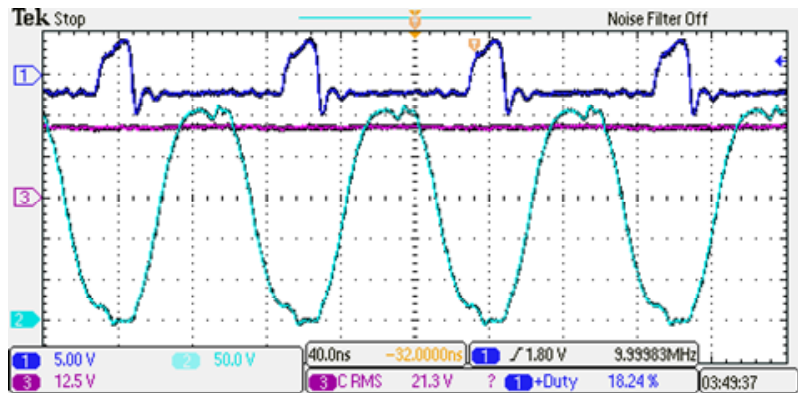

Fig. 18. Experimental waveforms for $V_{i n}=254 \mathrm{~V}$, Phase-shift $\Phi_{P-S}=25$ ns, $D_{p r i}=18 \%$. CH1: Gate-to-source signal of $S_{2}[5 \mathrm{~V} / \mathrm{div}]$; $\mathrm{CH} 2$ : Drainto-source waveform of $S_{2}$ [50 V/div]; CH3: Output voltage across $40 \Omega$ load $[12.5 \mathrm{~V} / \mathrm{div}]$

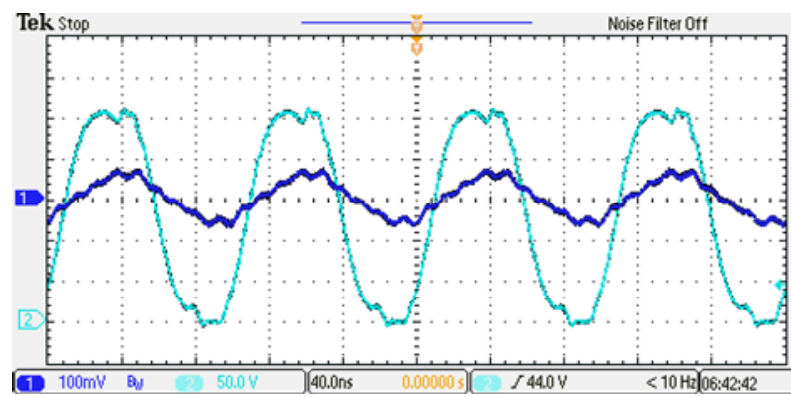

Fig. 19. Experimental waveforms for $V_{i n}=254 \mathrm{~V}$, Phase-shift $\Phi_{P-S}=25$ ns, $D_{p r i}=18 \%$. CH1: Resonant tank current [2 A/div] (dark blue); $\mathrm{CH} 2$ : Resonant tank voltage [50 V/div] (light blue).

\section{POWER LOSS BREAKDOWN}

The total loss breakdown for the proposed DC-DC converter at rated power is shown in Fig. 20. The driving loss is the total gate drive loss for both primary and secondary GaNFETs. The device losses include the total forward and reverse conduction loss, and switching loss due to all primary and secondary GaNFETs. The loss due to the power consumption in the auxiliary power supply 
is estimated to be $1 \mathrm{~W}$, the loss due to the ESR of the capacitors, and PCB traces are considered as additional conduction losses. The efficiency of the converter at an output power of $20.2 \mathrm{~W}$ is $85.27 \%$. The total power loss is $3.49 \mathrm{~W}$. Optimizing the inductor and auxiliary power supply (for powering the gate drivers) designs could further increase the efficiency of the converter. Integrating the transformer and inductor into a single magnetic structure will reduce the overall size of the magnetics. This also reduces the terminations by two and reduces the copper loss due to reduced number of windings. Winding resistance can be reduced by paralleling multiple layers in planar PCB windings. The power stage and magnetic designs can be further investigated by changing the constant $k$ described in Section III.

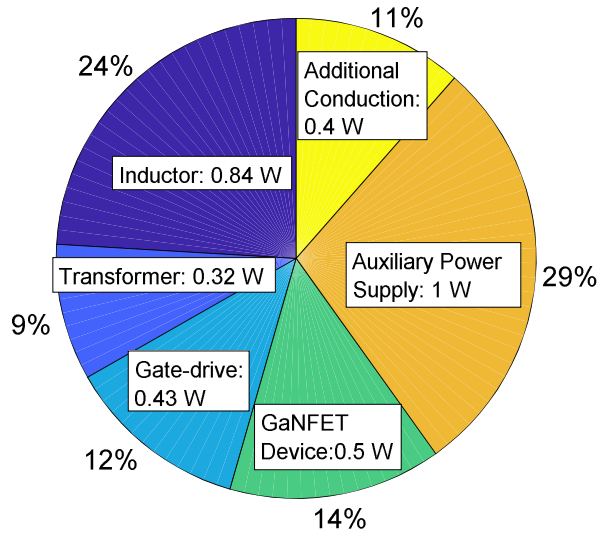

Fig. 20. Total loss breakdown for an output power $P_{\text {out }}=20.2 \mathrm{~W}$.

\section{CONCLUSIONS}

In this paper, a high-frequency, high-step down isolated DC-DC converter equipped with the $\mathrm{GaN}$ devices is analyzed and designed. The proposed resonant design shapes waveforms to optimize magnetics and achieve low EMI and high efficiency with high power density. The inductor and transformer are designed using commercially available materials to minimize the physical size and core and copper losses when operating at a switching frequency of $10 \mathrm{MHz}$. The core material Fair-Rite 67 was chosen from many of the commercially available magnetic materials because of its better performance factors and its availability in low-profile planar structures. Maxwell 3D simulations were performed to estimate the $\mathrm{AC}$ resistances of the inductor and transformer at $10 \mathrm{MHz}$. A phase shift angle between the primary and secondary GaNFETs was used to regulate the output voltage and power of the DC-DC converter. A $20 \mathrm{~W}, 300 \mathrm{~V}$ to $28 \mathrm{~V}$ laboratory prototype operating at $10 \mathrm{MHz}$ achieved an efficiency of $85.2 \%$.

\section{REFERENCES}

[1] Y. Zhang, J. Strydom, M. de Rooij and D. Maksimović, "Envelope tracking GaN power supply for $4 \mathrm{G}$ cell phone base stations," 2016 IEEE Applied Power Electronics Conference and Exposition (APEC), Long Beach, CA, 2016, pp. 2292-2297.

[2] EPC white paper, 2017. [Online]: http://epcco.com/epc/Portals/0/epc/documents/papers/eGaN\%20FETs\%20f or\%20Envelope\%20Tracking\%20Applications.pdf

[3] F. Gamand, M. D. Li and C. Gaquiere, "A 10-MHz GaN HEMT DC/DC Boost Converter for Power Amplifier
Applications," IEEE Transactions on Circuits and Systems II: Express Briefs, vol. 59, no. 11, pp. 776-779, Nov. 2012.

[4] K. Kruse, M. Elbo and Z. Zhang, "GaN-based high efficiency bidirectional DC-DC converter with $10 \mathrm{MHz}$ switching frequency," 2017 IEEE Applied Power Electronics Conference and Exposition (APEC), Tampa, FL, 2017, pp. 273-278.

[5] G. Calabrese, M. Granato, G. Frattini and L. Capineri, "Integrated high step-down multiphase buck converter with high power density," 2014 16th European Conference on Power Electronics and Applications, Lappeenranta, 2014, pp. 1-10.

[6] Y. Nour, Z. Ouyang, A. Knott and I. H. H. Jørgensen, "Design and implementation of high frequency buck converter using multilayer PCB inductor," IECON 2016 - 42nd Annual Conference of the IEEE Industrial Electronics Society, Florence, 2016, pp. 13131317.

[7] J. Millán, P. Godignon, X. Perpiñà, A. Pérez-Tomás and J. Rebollo, "A Survey of Wide Bandgap Power Semiconductor Devices," IEEE Transactions on Power Electronics, vol. 29, no. 5, pp. 2155-2163, May 2014

[8] R. C. N. Pilawa-Podgurski, A. D. Sagneri, J. M. Rivas, D. I. Anderson and D. J. Perreault, "Very-High-Frequency Resonant Boost Converters," IEEE Transactions on Power Electronics, vol. 24, no. 6, pp. 1654-1665, June 2009.

[9] M. Madsen, A. Knott and M. A. E. Andersen, "Low Power Very High Frequency Switch-Mode Power Supply With $50 \mathrm{~V}$ Input and 5 V Output," IEEE Transactions on Power Electronics, vol. 29, no. 12, pp. 6569-6580, Dec. 2014.

[10] D. C. Hamill, "Class DE inverters and rectifiers for DC-DC conversion," PESC Record. 27th Annual IEEE Power Electronics Specialists Conference, Baveno, 1996, pp. 854-860 vol.1.

[11] H. Koizumi, T. Suetsugu, M. Fujii, K. Shinoda, S. Mori and K. Iked, "Class DE high-efficiency tuned power amplifier," IEEE Transactions on Circuits and Systems I: Fundamental Theory and Applications, vol. 43, no. 1, pp. 51-60, Jan 1996.

[12] M. P. Madsen, A. Knott and M. A. E. Andersen, "Very high frequency half bridge DC/DC converter," 2014 IEEE Applied Power Electronics Conference and Exposition - APEC 2014, Fort Worth, TX, 2014, pp. 1409-1414.

[13] Juan Rivas, Radio Frequency dc-dc Power Conversion, Doctoral Thesis, Massachusetts Institute of Technology, 2006.

[14] Mickey P. Madsen, Very High Frequency Switch-Mode Power Supplies: Miniaturization of Power Electronics, Doctoral Thesis, Technical University of Denmark, 2015.

[15] I. O. Lee and G. W. Moon, "The $k$-Q Analysis for an LLC Series Resonant Converter," IEEE Transactions on Power Electronics, vol. 29, no. 1, pp. 13-16, Jan. 2014.

[16] M. Ekhtiari, Z. Zhang and M. A. E. Andersen, "Analysis of Bidirectional Piezoelectric-Based Converters for Zero-Voltage Switching Operation," IEEE Transactions on Power Electronics, vol. 32, no. 1, pp. 866-877, Jan. 2017.

[17] C. R. Sullivan, D. V. Harburg, J. Qiu, C. G. Levey and D. Yao, "Integrating Magnetics for On-Chip Power: A Perspective," IEEE Transactions on Power Electronics, vol. 28, no. 9, pp. 4342-4353, Sept. 2013.

[18] F. C. Lee and Q. Li, "High-Frequency Integrated Point-of-Load Converters: Overview," IEEE Transactions on Power Electronics, vol. 28, no. 9, pp. 4127-4136, Sept. 2013.

[19] A. J. Hanson, J. A. Belk, S. Lim, C. R. Sullivan and D. J. Perreault, "Measurements and Performance Factor Comparisons of Magnetic Materials at High Frequency," IEEE Transactions on Power Electronics, vol. 31, no. 11, pp. 7909-7925, Nov. 2016.

[20] Y. Han, G. Cheung, A. Li, C. R. Sullivan and D. J. Perreault, "Evaluation of Magnetic Materials for Very High Frequency Power Applications," IEEE Transactions on Power Electronics, vol. 27, no. 1, pp. 425-435, Jan. 2012.

[21] "Soft ferrites and accessories data handbook," Ferroxcube Int Holding B.V., Eindhoven, The Netherlands, Tech. Rep. FXC 100 $00002,2013$.

[22] Material data sheets. Fair-Rite Products Corp. (2016). [Online]. Available: http://www.fair-rite.com/newfair/materials.htm.

[23] HF Capacitor datasheet, AT Ceramics (2018). [Online]. Available: http://www.atceramics.com/UserFiles/100c.pdf

[24] HF Capacitor datasheet, AT Ceramics (2018). [Online]. Available: http://www.atceramics.com/UserFiles/900c.pdf.

[25] Gate-driver: http://www.ti.com/product//m5114. 